\title{
MAINTENANCE OF WORK EQUIPMENT BASED ON VIBRATION DIAGNOSIS FOR THE PURPOSE OF EMPLOYEES' SAFETY
}

\author{
UDC 534.843:941.546.4
}

\author{
Žarko Janković, Milan Mišić, Miljan Cvetković \\ University of Niš, Faculty of Occupational Safety, Niš, Serbia \\ Colege for Applied Technical Science Zvečan, Serbia
}

\begin{abstract}
Maintenance of work tools and equipment is one of the major measures that can significantly affect the safety and health of employees. However, if we do not pay enough attention to this problem, the consequences could be improper functioning of the equipment, which, due to failure can cause the breakdown and employees' injuries. For this reason, the paper pays special attention to preventive maintenance and failure analysis of vital parts, equipment and tools. In addition to the concept of preventive maintenance, which is given importance in the work, this paper focuses on the concept of equipment maintenance based on reliability. Several examples of improper maintenance of equipment and failures that can lead to serious consequences for both employees and have been presented here.
\end{abstract}

Key words: equipment maintenance, preventive maintenance, layoffs, employee safety

\section{INTRODUCTION}

Maintenance of work tools and equipment involves implementation of technical and administrative activities in order to complete a certain function without failure for a specified period of operation. In other words, maintenance of the equipment represents a "combination of technical and administrative activities during the life cycle of equipment for work that needs to keep its state in which it can perform its function," [1]. Apart from these wide consequences, maintenance of work equipment plays an important role that influences the safety and health of not only the employees who are directly involved in the maintenance, but also other employees in the company. Occupational injuries can occur during the maintenance process in various cases, for example: employees who perform maintenance jobs on machines can be injured if the machine is accidentally started, they are exposed to hazardous substances or if they have to take a nonphysiological posture of their body during work. Poor quality of maintenance may also

Received April 4, 2017 / Accepted July 13, 2017

Corresponding author: Miljan Cvetković

Faculty of Occupational Safety, Čarnojevića 10a, 18000 Niš, Serbia

E-mail: miljan.cvetkovic@znrfak.ni.ac.rs 
contribute to serious consequences (e.g. if inappropriate parts for replacement or repair of machinery are used). Failure to perform maintenance shortens the life of equipment and facilities which may cause accidents and threaten the environment Maintenance has two very important roles. Firstly, regular maintenance, which is properly planned and performed is very important since it ensures safe and reliable operations. Secondly, the maintenance of the should be safely carried out, provided with adequate protection for maintenance staff as well as all persons who find themselves in the space.

\section{CONCEPTS OF EQUIPMENT MAINTENANCE}

Historically, the concept of the maintenance system has been developed from the simplest - corrective approach to restore the system from the state of the termination of the state of the work, to the most complex - the concept of self-preservation. Only the concept of maintaining work equipment is shown in Figure 1.

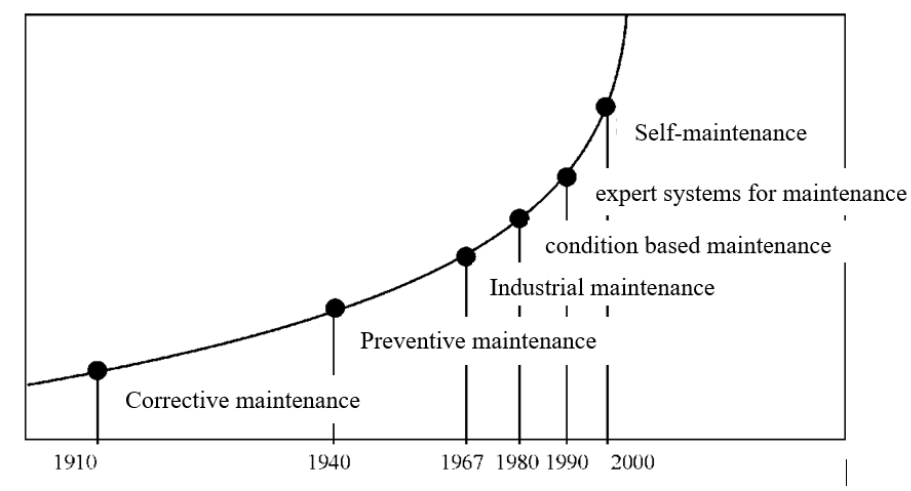

Fig. 1 The development of the concept of maintenance

As seen in the Figure 1, the concept of equipment maintenance has been changing throughout time. At the beginning of the last century, the maintenance was mainly enforced in case of equipment failure. The equipment was usually repaired for its reuse. Only in the middle of the last century did preventive maintenance, repairs and replacement of parts before the fault (dismissal) become significant. The rapid development of industry in the sixties raised the concept of industrial maintenance. Considering the problems in this area in the eighties, the maintenance concept referred to the state in which the equipment was able to perform its intended function. Development of science, especially in the nineties, contributed to the concept of expert system maintenance. At the beginning of the twentyfirst century, the maintenance was given a completely different concept which was focused on self-maintenance. The future of maintenance is difficult to predict, due to new developments and rapid replacement of obsolete equipment.

The concept of self-maintenance is related to the "robotic" way of production. The reason for this attitude lies in the fact that all new technical systems and equipment in addition to basic functions, have functions whose purpose is self-diagnostics of embedded parts. Secondly, an important prerequisite for the realization of self-maintenance concept is 
new technology that makes space for diagnosis and self-repair - more exactly cloning machine parts and performing work without the presence of workers ("factories without people").

During its lifetime, the equipment is exposed to broad spectrum of external and internal disturbances, leading to discrepancies in their basic characteristics and parameters of the state from its nominal (permissible) values. In the ongoing pursuit of users to maintain the system performance within the permissible deviations or return it to the (desired) interval, various systems of maintenance have been developed depending on the characteristics of applied concept, technology and maintenance organization [2].

Maintenance of technical system includes procedures, methods and techniques that ensure the correct operation of the system in a certain period of time, in order to prevent or delay the system failure (preventive maintenance) and repair (corrective maintenance).

Choosing the concept of preventive maintenance and applying the appropriate models in technical systems can contribute to positive effects in terms of increasing safety and reducing maintenance costs. In the initial development of the industrial systems, maintenance was considered a secondary activity, and the impact of maintenance on production efficiency and increased productivity was considered insignificant. Nowadays, however, maintenance of the equipment occupies an important place in the production system. This is explained by the fact that the slow growth of industrial production, together with the rising price of raw material and reduction of capacity, may be slightly improved by efficient maintenance of work equipment, which is an integral feature of the production process. The starting point is the fact that the maintenance is a part of total production, and that it is defined as the permanent control of the work tools which, if necessary, should be subjected to certain repairs to keep up with a continuous production process and increase the safety of employees.

Among all activities that accompany the production, maintenance has been receiving increasing importance and there is no doubt that it has aroused interest due to its ability to significantly extend the lifetime of machinery and equipment in all sectors of production. Later, the vision of the maintenance process changed with the introduction of mechanization and automation and increased number of machines being used. Development of industry brought about an organized manner of maintenance that have a preventive role in the function of security.

Equipment maintenance involves primarily the concept of maintenance, which essentially represents the moment in which the decision to maintain is being made: before failure (preventive maintenance), after the failure (corrective/ recovery maintenance) or combined. Technological aspects of maintenance is reflected in the type and method of performing maintenance procedures. One can say that the maintenance includes procedures, methods and techniques that ensure the correct operation of technical systems in a given period of time, in order to prevent cancellation. There are several concepts of maintenance, among which the following two concepts are prevailing (corrective and preventive)

Corrective maintenance means that the activities are aimed at the renewal of work equipment when it fails to function properly (e.g. the repair or replacement of damaged parts). This concept of maintenance is also known as "reactive maintenance" because the maintenance activity begins when an unexpected termination (malfunction) happens. Correction is made after the failure so that the equipment could be functional and used in a safe manner. This is an unscheduled maintenance concept that usually brings greater danger and risk to employees in relation to the concept of preventive maintenance. 
Preventive maintenance implies that activities are carried out at predetermined time intervals or according to prescribed criteria to minimize possible untimely failure (fault). In this case, the maintenance activities are pre-planned, proactive and focused on the process of equipment monitoring (e.g. replacement, lubrication, cleaning and checks).

Monitoring and diagnostics by means of vibration

Monitoring the condition of machinery and equipment is only one of the activities that are part of technical maintenance which implies measuring and analyzing vibration frequencies vibrations. In principle, vibrations appear in seven main groups of activities within the technical maintenance of mechanical systems, those being:

1. Monitoring the condition of machines and equipment

2. Diagnostics of machines and equipment

3. The balancing of the impeller with vibration signal

4. Detection of the sources of vibration

5. Detection of acoustic emission sources

6. Modal analysis

7. The ultrasonic detection of damage

Each group of activities has certain limitations, both in terms of achieving the goals and tasks as well as the possibility to display the basic characteristics of vibration in order to achieve optimal results. For the presentation of the results, it is necessary to separate the symptoms of vibration frequency and manner of their occurrence. In terms of frequency, there are four bands or ranges: the low frequency range, the range of medium frequency, the range of high frequency and the range of ultrasonic frequency. According to the mode of occurrence, vibrations could be of natural origin (caused by dynamic processes in machines) and artificial vibrations triggered by special sources - oscillators. Natural vibrations are used to study the problems within the first five groups of the abovementioned activities in technical maintenance of machines, while the artificial vibrations are applied in the remaining two cases.

\section{MONITORING OF MACHINE CONDITION -VIBRATION ANALYSIS}

Machine condition monitoring is the process of monitoring the condition of a machine with the intent to predict mechanical wear and failure. The objects of monitoring machine condition in terms of its vibrations are machinery and equipment that are the sources of vibrations. These machines have vibration forces caused by e.g. movement of the individual elements, flow of fluid, or as a result of the operation of an alternative magnetic field. In rare cases, the monitoring object may be equipment that is not itself a source of vibration force and vibration, which operation is influenced by other sources of vibrations from the environment.

The aim of machine condition monitoring by vibration is to detect the changes in vibrations present in the object that is being tested. The causes of such changes are most commonly consequences of certain defects. Machine condition monitoring is carried out by performing first vibration test at low and medium frequencies that are very well spread from their place of origin to the place of control The number of such places near each machine can be reduced to one or two if the machines have a common housing. Vibration measurements can be performed without any changes to the operation of the facility. If this is not contained in the system of immediate protection, the monitoring system can be 
fitted with (instrument) a measuring wheel (an instrument) through which all connected inverters will be used in the monitoring system. This procedure dramatically reduces the price of the monitoring system, while not reducing the reliability of the results obtained.

The task of the system for monitoring the condition is to:

- Measure the sizes important for reliable operation of individual plants.

- Analyze measurement signals, or calculate certain parameters that allow direct assessment of the situation of each facility / equipment.

- Alarm, or trigger the operating part of the plant (protections, controls) in the case of impermissible level or the mutual relations of controlled size.

\subsection{Systems for continuous monitoring of the condition}

Systems for continuous (ongoing, continuous, on-line) monitoring are commonly installed on new installations or already existing installations.

One of the areas with intensive development of a system for monitoring the condition is the area of monitoring mechanical quantities, especially vibrations. The leader is the development of a system for monitoring the status of power plants (turbo and hydro aggregates, pumps, fans and a large fig.). These systems can be divided into:

- Conventional systems for monitoring

- Systems for diagnostic monitoring.

Schematic representation of the components of a complete system for monitoring the status is shown in Figure 2.

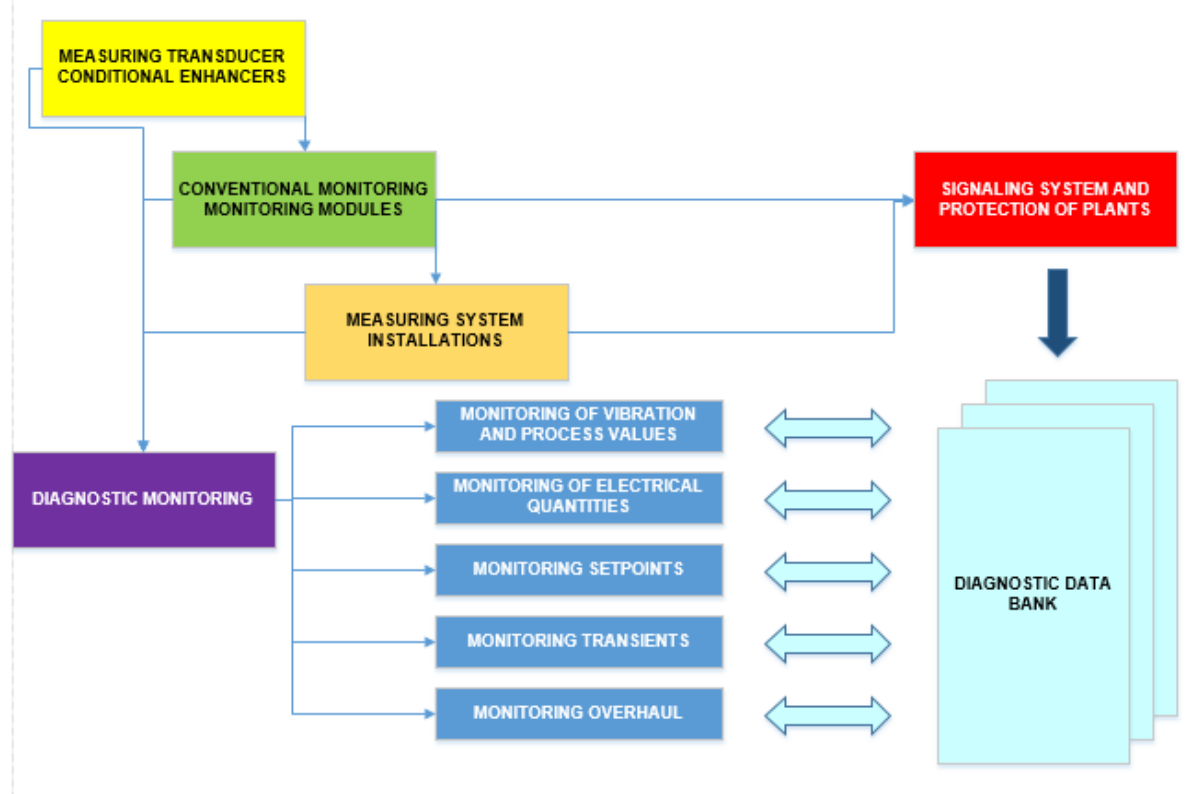

Fig. 2 Block diagram of a complete system for continuous condition monitoring 


\subsection{Systems for controlling conventional monitoring}

Conventional monitoring systems consist of:

- Measuring transducer, which have the task of measuring

- Modules, which have the task of accepting and adjusting (conditioning) signal from the measuring encoder, their basic processing, comparing with the standards prescribed values, and alarm activation and execution protection.

Such systems are commonly saved as separate "hardware" of the unit.

Conventional monitoring is carried out according to current applicable standards. For monitoring the condition of rotating machinery, we use the standards ISO 13373-1: 2002 which contains general procedures and ISO 13373-2: 2005which contains the methods of processing, analysis and presentation of vibration data. The primary purpose of these systems is protection against excesses, or activation of signal switching and protection in case when monitored magnitude exceeds the value of this type of facility permitted to the appropriate standard

\section{THE IMPACT OF MAINTENANCE ON SAFETY AND HEALTH AT WORK}

Maintenance is carried out in all sectors and at every workplace. This is not the exclusive domain of maintenance technicians and engineers, since maintenance is included in the daily tasks of most employees. Therefore, employees who work on maintaining are exposed to a wide range of hazards and damage (mechanical, chemical, physical, biological or psychological). Employees who perform maintenance can be at risk of:

- Occurrence of diseases of the musculoskeletal system working in adverse postures of the body, sometimes in difficult weather conditions (e.g. cold)

- Occurrence of respiratory problems that are related to exposure to asbestos (e.g. Maintenance of old buildings or industrial facilities)

- Occurrence of skin diseases due to contact with dangerous and harmful chemical substances (fats, oils, solvents, acids, etc.)

- Diseases that are the result of exposure to biological hazards

- Various types of injuries, including falls from height, slipping, tripping, hitting the moving parts of equipment and machinery.

Therefore, the maintenance staff are exposed to the risks of developing various types of injuries. The possibility of injury from moving machine parts that can cause injury or death should be borne in mind at all times.

Regardless of whether the maintaining activities are small or extensive, they could adversely affect the safety and health of not only the employees who perform these activities, but also other persons who are in the area. The injuries of maintenance staff can occur in different cases, namely: in the random startup equipment, exposure to ionizing radiation or hazardous substances. Poor maintenance can cause safety problems, for example in case of inappropriate parts for replacement or repair which can cause serious injury to employees and damage to the equipment.

The persons employed at maintenance are exposed to noise, vibration, radiation, hazardous substances, vapors and gases. However, despite these identification employees who work on maintaining the open space could mention the heat in summer, cold in winter and humidity. The data show that about $20 \%$ of all occupational injuries occur in 
connection with maintenance. Statistical figures from several European countries show that about $10-15 \%$ of all fatal injuries were related to maintenance, [3].

Scientific studies suggest that the diseases and health problems related to work (such as asbestosis, cancer, hearing problems and diseases of the muscular - skeletal system) are also most common among the employees who deal with maintenance. For example, in the activities in the energy sector (services for supply of electricity, gas and water), the maintenance jobs have the largest number of injuries.

The question of when it is the right time to start maintenance is always significant. It is recommended that the maintenance process should begin in the design stage and planning before employees begin maintenance work. It is essential to perform appropriate risk assessment procedure related to maintenance, as well as to take into account relevant preventive measures to ensure the safety and health of employees involved in maintenance. Since maintenance tasks are completed, special checks (visual inspection and trial testing the functioning of technical systems) should be carried out to make sure that the maintenance is properly performed and that there were no new risks. Throughout the maintenance process, we should take into account whether the maintenance was carried out as planned and whether the equipment and jobs were left in a safe condition. More details and information about this are given in http://www.cen.eu [5].

\section{SAFE MAINTANCE}

Safe maintenance is a process that begins before an actual work and ends after the verification and record of activities and technical documentation. Participation of employees in all phases of maintenance increases not only the safety of the process but also the quality of work.

Hereinafter described are the rules for safe maintenance relating to:

- Maintenance plan,

- Work in safe conditions,

- Use of appropriate equipment,

- Compliance with safe work procedures,

- Inspecting the quality of work.

a) Maintenance plan

As part of planned maintenance, it is necessary to make a risk assessment for all activities on maintenance of work equipment. In this activity, it is necessary to involve all employees and consider the following:

- Consider the volume of tasks that need to be performed, time required and how it will affect other employees and jobs in the workplace.

- Identify the hazards and harmful effects of electricity, exposure to hazardous substances, the presence of dust / asbestos in the air, limited space, moving machine parts, the fall from a height or through the floor, heavy objects to be moved, parts which are inaccessible or difficult to reach.

- To determine what is required to perform maintenance (required expertise and the number of employees in maintenance, who will be involved, what role individual persons have, responsibility of the contractor or the customer for contacts with employees, management tasks, information about potential problems, tools to be 
used, means and equipment for personal protection at work, and other measures of health and safety at work which may be necessary).

- Secure access to the work zone and method for rapid evacuation in case of emergency.

- Enable all employees who work directly in maintenance and inform all those who work near them about the jobs (to ensure competence of employees and their safety), the responsibilities and all the procedures that will be used during the maintenance process, including reporting problems. This is especially important if the maintenance is performed by a subcontractor.

All employees of the maintenance should be included in the planning phase of maintenance because they are best placed to recognize the danger and harmfulness of the most effective ways to overcome them. Analysis of risk assessment and planning phase of the document to be delivered to employees who participate in the performance of maintenance, as well as other employees that maintenance can be affected. Involving employees together with subcontractors in training and familiarization with the established procedures are very important elements in ensuring their safety.

b) Work in safe conditions

Procedure as defined in the risk assessment should be applied in practice during maintenance. For example, make sure you must turn off the power source of energy of all technical systems which perform maintenance process and according to the agreed procedure. It is necessary to set up a visual warning label (date and time of exclusion and name of the person authorized to remove the ban placed an inscription). Employees should check whether there is a safe entrance to and exit from the working zone, in accordance with the execution plan.

c) Use of proper equipment

Employees who perform maintenance tasks need to have the proper tools and protective equipment, which may differ from those commonly used. This is because the work in the maintenance may be performed in a space that is not an ordinary workplace, where employees are exposed to many dangers and hazards. Therefore, employees must have adequate means and equipment for personal protection at work. For example, employees who clean or replace filters on the exhaust fan may be exposed to dust concentrations that are much higher than normal in this workplace. Access to these filters, often located on the roofs, must also be safe. Tool required for operation and means and equipment for personal protection at work that have been identified in the planning and risk assessment must exist (along with instructions for use, if necessary) and must not be used.

\section{d) Compliance with safe work procedures}

Procedures for safe operation adopted in the planning phase must be applied. Work Plan and the agreed deadlines must be respected. The activities should not be performed faster than the standardized time and procedures which it intended, because each "shortcuts" in business can cost a lot and lead to employee injuries or property damage. It is essential that line managers and / or other experts consulted in the event that something unexpected happens from the planned procedures. It is very important to respect the expertise and competence with command responsibility for the maintenance in order to avoid serious consequences. 
e) Inspecting quality of work

After the maintenance, each job needs to be reexamined. The verification should be done to make sure that the task is completed, whether the part where the maintenance was carried out is in a functional and safe condition and whether the material that emerged during maintenance was removed. Once the checks have been completed and warnings removed, a normal working process can start. The report should describe the work done and give remarks about the difficulties at work as well as recommendations for improvement. This issue should be talked about this at a meeting attended by all the employees who were involved in the maintenance process, as well as those who work near them, so that they can give their comments and suggestions relevant to the maintenance process equipment improved.

Given the relatively large number of hazards and harmful effects that influence the risk for employees working on maintenance, it is necessary to take into account the estimated risk management. Before beginning maintenance work, it is necessary to do a detailed assessment of the risks and to include all phases of the business and all the dangers and harmful effects. This is particularly important to do in small and mediumsized enterprises because of their huge losses in case of injuries during maintenance.

Competence of employees who perform maintenance, including medical examinations and training is vital to safety. Although employees often have expertise in several areas, their competence for maintenance must be specially emphasized in the description of their tasks. However, the employees need to undergo additional trainings for the tasks they do not perform regularly. This is because employees are often at risk of injuries if they try to perform tasks that are not trained or for which they do not have experience. Employers must check whether employees have the expertise to perform the necessary tasks, whether they are informed of the hazards and safe work procedures and whether they know what to do in situations that go beyond their expertise.

Employees often work on maintaining the high-risk areas. For these reasons, these works require the use of work equipment which is normally not used in the workplace, including means and equipment for personal protection at work. Procurement procedures must exist to ensure that there are necessary tools and means of personal protection equipment provided to employees in the maintenance of technical systems. For example, sometimes temporarily lighting should be used in the explosion protection or appropriate personal protective equipment (e.g. respiratory protection when cleaning the filters). The risk during maintenance should be reduced to a minimum or even eliminated through a well-constructed equipment for work, the existence of appropriate tools and instructions from the manufacturer.

\section{CONCLUSION}

It is crucial to consider the maintenance as a process, not just a task that must be done temporarily. The maintenance process begins with the planning phase, and it includes comprehensive risk assessment. It is recommended that employees who work on maintaining or their representatives should be involved in the planning maintenance process. Procedures for maintenance must be respected, but conditions for solving the unexpected problems should also be present. Once the maintenance is completed, the functioning operations must be checked to make sure that the equipment or machinery 
and equipment are safe to be reused. Also, the waste material should be removed, the area cleaned and trial operation conducted in order to keep up with the normal functioning.

The situation that can have negative impact on the safety of the employees is the fact that maintenance is often carried out within deadlines - "under pressure" - in order to quickly re-start the production process or to complete the job before the planned deadline. This problem increases if employees use work resources without necessary protective system. Risk assessment is done to prevent the possible consequences, to ensure that maintenance is performed safely and that employees who are engaged in the ongoing production process are not endangered, and that the equipment can be used again safely. The Risk Assessment Act for maintenance employee's jobs should be kept together with the documentation on equipment maintenance.

Key elements in terms of safety and health of the staff employed at maintenance are: training and defining the competence of employees working on maintenance, and respecting the safe work based on risk assessment. After the maintenance jobs are completed, specific checks (examinations and tests) need to be performed to make sure that the maintenance was carried out properly and that the equipment or workplace are left in a safe condition for future operations.

In the end, we can conclude that employers who do not maintain their work tools and equipment, especially those parts that are related to safety (e.g. safety systems and alarms), are at greater risks that equipment failure will be catastrophic for all employees.

\section{REFERENCES}

1. International Information Center of Safety and Health at Work: www.ilo.org/cis.

2. The European Agency for Safety and Health at Work (Bilbao, Spain): www.europe.osha.int

3. The European Foundation for the improvement of living and working environment (Dublin, Ireland) www.eurofound.ie

4. http://www.cdc.gov/niosh/homepage.html (access 09.20.2016).

5. http://osha.europa.eu/en/topics/maintenance (access 09.20.2016)

6. http://www.cen.eu (access 09.20.2016)

\section{ODRŽAVANJE OPREME I SREDSTAVA ZA RAD ZASNOVANO NA VIBRACIJAMA U FUNKCIJI BEZBEDNOSTI ZAPOSLENIH}

Održavanje opreme i sredstava za rada je jedna od važnih mera koja značajno može uticati na bezbednost $i$ zdravlje zaposlenih. Međutim, ukoliko se ovom problemu ne posvećuje dovoljno pažnje posledice su izražene na nepravilno funkcionisanje opreme, koja usled otkaza može prouzrokovati havariju i povrede zaposlenih. Iz tih razloga, u radu se posvećuje posebna pažnja preventivnom održavanju i analizi otkaza vitalnih delova opreme i sredstava rada. Pored koncepta preventivnog održavanja kojem je dat značaj u radu, ukazano je na koncept održavanja opreme na bazi pouzdanosti. U radu je dato nekoliko primera nepravilnog održavanja opreme i grešaka koje mogu dovesti do teških posledica kako za zaposlene tako i društvo u celini.

Ključne reči: održavanje opreme, preventivno održavanje, otkazi, bezbednost zaposlenih 